\title{
Bench Tests of Simple, Handy Ventilators for Pandemics: Performance, Autonomy, and Ergonomy
}

\author{
Erwan L'Her MD PhD and Annie Roy RRT
}

\begin{abstract}
BACKGROUND: It has been pointed out that in the wake of a virulent flu strain, patients with survivable illness will die from lack of resources unless more ventilators are made available. Numerous disaster-type ventilators are available, but few evaluations have been performed. $\mathrm{OB}$ JECTIVE: To compare simple, lightweight, and handy ventilators that could be used in the initial care of patients with respiratory distress. METHODS: We bench-tested 4 volume-cycled ventilators (Carevent ALS, EPV100, Pneupac VR1, and Medumat Easy) and 2 pressure-cycled ventilators (Oxylator EMX and VAR-Plus). We studied their general physical characteristics, sonometry, gas consumption, technical performance, ergonomy, and user-friendliness. With a test lung we assessed performance at $\mathrm{F}_{\mathrm{IO}_{2}}$ of 0.50 and 1.0, set compliance of 30, 70, and $120 \mathrm{~mL} / \mathrm{cm} \mathrm{H}_{2} \mathrm{O}$, and set resistance of 5, 10, and $20 \mathrm{~cm} \mathrm{H} / \mathrm{O} / \mathrm{L} / \mathrm{s}$. To study user-friendliness and ergonomy we conducted, in randomized order, 7 or 8 objective, quantitative tests and 2 subjective tests. RESULTS: Compliance and resistance strongly affected tidal volume with the pressure-cycled ventilators (from $418 \pm 49 \mathrm{~mL}$ to $1,377 \pm 444 \mathrm{~mL}$ with the VAR-Plus, at the lowest pressure level), whereas the volume-cycled ventilators provided a consistent tidal volume in the face of changing test lung characteristics. CONCLUSIONS: We are concerned that the pressure-cycled ventilators did not provide a consistent tidal volume, and under certain conditions the volume delivered would be unsafe (too large or too small). Most of the volume-cycled ventilators proved to be technically efficient and reliable. Their reliability, portability, and ease of use could make them valuable in natural disasters and mass-casualty events. Key words: mechanical ventilator; mass-casualty event; pandemic; influenza; emergency; disaster. [Respir Care 2011;56(6):751-760. (ㅇ 2011 Daedalus Enterprises]
\end{abstract}

\section{Introduction}

Following September 11, 2001, and various biological alerts, the worldwide medical community has taken steps

Dr L'Her is affiliated with the Département de Médecine Familiale et Médecine d'Urgence, Université Laval, Québec, Canada; Centre de Recherche du Centre Hospitalier Affilié Universitaire Hôtel-Dieu de Lévis et Centre Hospitalier Affilié l'Hôpital de l'Enfant-Jésus, Québec, Canada; and with Pôle Urgences-Service d'Aide Médicale Urgente, Centre Hospitalier Universitaire de la Cavale Blanche, Brest, France. Ms Roy is affiliated with Centre de Recherche du Centre de Recherche du Centre Hospitalier Affilié Universitaire Hôtel-Dieu de Lévis et Centre Hospitalier Affilié l'Hôpital de l'Enfant-Jésus, Québec, Canada.

This work was partly supported by the Chaire de Recherche en Médecine d'Urgence, Hôtel-Dieu de Lévis, Université Laval, Québec, Canada.

The authors have disclosed relationships with Allied Healthcare, Smiths Medical, Weinmann Geräte für Medizin, Lifesaving Systems, and Vor- to prepare for events that would create numerous critically ill patients. ${ }^{1}$ Recently, the threat of viral pandemic (eg, severe acute respiratory syndrome, avian flu [H5N1], and

See the Related Editorial on Page 879

H1N1), which might result in thousands of patients requiring mechanical ventilation, has accelerated preparations. Even with a $10 \%$ pandemic influenza rate, a $5 \%$ admission

\footnotetext{
tran Medical Technology, which donated the tested ventilators. The authors have disclosed no other conflicts of interest.

Correspondence: Erwan L'Her MD PhD, Réanimation Médicale, Centre Hospitalier Universitaire de la Cavale Blanche, 29609 Brest, France. E-mail: erwan.lher@chu-brest.fr.
}

DOI: $10.4187 /$ respcare. 00841 


\section{Bench Tests of Simple, Handy Ventilators for Pandemics}

rate to critical care units, and maximum increased resources available, a major mismatch between supply and demand may occur. ${ }^{2}$ The worst-case scenarios, described by various experts, may have a $30 \%$ admission rate, which would rapidly overwhelm critical care resources, especially ventilators, so many patients with survivable illness would die from lack of ventilators. ${ }^{1}$

Hospitals have almost no reserve ventilators to respond to disaster or pandemic. Critical-care ventilators are complex and designed to support patients with a wide range of medical conditions, but their high cost makes it impossible to stockpile them, so a simple, low-cost, but efficient ventilator is of major interest.

When dealing with an unstable acute-respiratory-failure patient, a ventilator setting error or malfunction may cause patient injury or death. The extensive training and competency required to safely and effectively operate a ventilator impedes the use of support personnel in a masscasualty event. Even with recurrent ventilator education, personnel cannot be assumed to be up to date with such low frequency of use, ${ }^{3,4}$ so optimal ergonomy and userfriendliness is crucial to minimize the risk of human error. A contrario, an easy-to-use ventilator that cannot safely and effectively ventilate the patient is not a good choice.

We bench-tested 6 simple, lightweight, handy ventilators designed for mass-casualty events. We studied the ventilators' physical characteristics regarding stockpile requirements, gas autonomy, technical performance, reliability, ergonomy, and user-friendliness.

\section{Methods}

We measured each ventilator's device volume with a laser distance-meter (Disto A6, Leica, St Gallen, Switzerland). For stockpiling, the important factor is the cubic volume of the ventilator's actual storage space, as opposed to just the exact device volume. Weight was measured with an electronic scale (PD750, My Weight, Phoenix, Arizona).

We measured the normal operational and alarm noise with a factory-calibrated class II sonometer (Digital Sound Meter, Extech, Waltham, Massachusetts), in the fast recording mode (response time $200 \mathrm{~ms}$ ), at the normal human ear frequency. The sonometer unit was set on a tripod at the center of a $37-\mathrm{m}^{3}$ room, $1.25 \mathrm{~m}$ above the floor, $70 \mathrm{~cm}$ from the center of the ventilator. The sonometry data were collected with dedicated acquisition software and recorded continuously for $10 \mathrm{~min}$ after stabilization of the signal. Sonometry was carried out during normal and alarm ventilator operation, at $\mathrm{F}_{\mathrm{IO}_{2}}$ of 0.50 and 1.0.

We measured the output gas temperature with a fastresponse thermometer (SmartReader Plus 5 Data Logger, ACR Systems, Surrey, British Columbia, Canada), with the probe inserted immediately after the flow output, for a 2-hour period, and we calculated the mean temperature over that period. We measured $\mathrm{F}_{\mathrm{IO}_{2}}$ with a calibrated oxygen analyzer (Oxiquant S, Envitec, Wismar, Germany).

\section{Autonomy}

Of the tested ventilators, only the EPV100 (which runs on 2 standard D-cell batteries) uses electrical power. We measured the gas consumption with standardized ventilation settings: tidal volume $\left(\mathrm{V}_{\mathrm{T}}\right) 500 \mathrm{~mL}$; respiratory rate 15 breaths/min; $\mathrm{F}_{\mathrm{IO}_{2}} 0.5$ or 1.0 . We used an E-size oxygen cylinder and operated each ventilator until effective ventilation ceased or $\mathrm{V}_{\mathrm{T}}$ was decreased by $10 \%$. We recorded duration of operation in minutes, and calculated the mean oxygen consumption assuming $642 \mathrm{~L}$ of gas in the cylinder. Measurements were performed twice with each ventilator and each $\mathrm{F}_{\mathrm{IO}_{2}}$.

\section{Performance}

Performance was assessed with an automated test lung (ASL 5000, Ingmar, Pittsburgh, Pennsylvania), at $\mathrm{F}_{\mathrm{IO}_{2}}$ of 0.5 and 1.0 (if available), at set compliances of 30,70 , or $120 \mathrm{~mL} / \mathrm{cm} \mathrm{H}_{2} \mathrm{O}$, and set resistances of 5 , 10 , or $20 \mathrm{~cm} \mathrm{H}_{2} \mathrm{O} /$ $\mathrm{L} / \mathrm{s}$, and constant PEEP of $10 \mathrm{~cm} \mathrm{H}_{2} \mathrm{O}$ via a reusable PEEP valve (AmbuPEEP, Ambu, Ballerup, Denmark) for volume-cycled ventilators. Pressure-cycled ventilators induce an automatic and non-adjustable PEEP value, which makes such measurements impossible to carry out with external PEEP. All measurements were performed at atmospheric pressure, constant room temperature $\left(22^{\circ} \mathrm{C}\right)$, and constant lung temperature (cylinder temperature $37^{\circ} \mathrm{C}$ ).

We measured $\mathrm{V}_{\mathrm{T}}$ and peak inspiratory pressure (PIP) with the pressure and flow transducers in the test lung, which we calibrated daily, according to standard procedures. We calculated the mean $\pm \mathrm{SD} \mathrm{V}_{\mathrm{T}}$ from at least 20 stable breaths. We analyzed the measurements and curves with graphics software (LabView, National Instruments, Austin, Texas) and the data-acquisition software in the test lung (version 3.0.3.d).

\section{Ergonomy and User-Friendliness}

We conducted, in a randomized order, 7 or 8 objective, quantitative tests (test duration, in seconds) and 2 subjective ventilator-user tests. Each ventilator was tested by 6 senior respiratory therapists and 6 senior emergency physicians, none of whom had experience with these ventilators nor other ventilators by the same manufacturers; we particularly emphasized this point because we wanted to make the tests like a real mass-casualty situation, in which the ventilator needs to be set up and operated easily by each professional aware of a ventilator's general functioning. We chose the objective tests most relevant to our field 


\section{Bench Tests of Simple, Handy Ventilators for Pandemics}

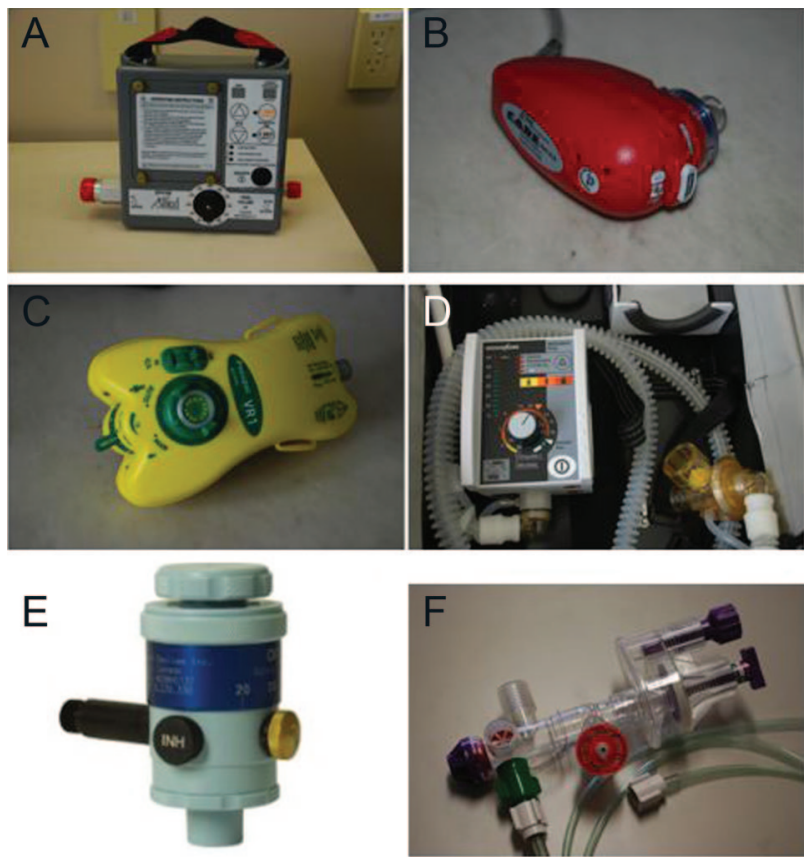

Fig. 1. A: EPV100. B: Carevent ALS. C: Pneupac VR1. D: Medumat Easy. E: Oxylator EMX. F: Vortran VAR-Plus.

of interest: circuit installation; ventilator on/off; identification of ventilation mode; identification of current ventilation settings; modification of $\mathrm{V}_{\mathrm{T}}$, PIP, and PEEP; identification of current alarm settings; and turn off and reset alarm. In each objective test, the clinician had 180 seconds to execute the task, after which the task was considered failed. We measured the time to complete each task.

In the subjective tests we asked the subjects their opinions on each ventilator's ease of use, on a scale of 1 (very difficult) to 5 (very easy), and their willingness to use that ventilator, on a scale of 1 (certainly not) to 5 (certainly).

\section{Ventilators}

We tested 6 ventilator models:

- Carevent ALS, O-Two Medical Technologies, Mississauga, Ontario, Canada

- EPV100, Allied Healthcare, St Louis, Missouri

- Pneupac VR1, Smiths Medical, Whatford, United Kingdom

- Medumat Easy, Weinmann Geräte für Medizin, Hamburg, Deutschland

- Oxylator EMX, Lifesaving Systems, Roswell, Georgia

- VAR-Plus, Vortran Medical Technology 1, Sacramento, California

The ventilators (Fig. 1) were donated by the manufac- turers. All the ventilators are small and have few settings. With the volume-cycled ventilators (Pneupac VR1, Carevent ALS, EPV100, and Medumat Easy) the $\mathrm{V}_{\mathrm{T}}$ and respiratory rate are dependent values, and only the Pneupac VR1 allows air-mixing $\left(\mathrm{F}_{\mathrm{IO}_{2}} 0.5\right)$. With the pressurecycled ventilators (Oxylator EMX and VAR-Plus) the inspiratory pressure level can be adjusted. The respiratory rate can be slightly adjusted on the VAR-Plus, but needs to be controlled, whereas the initial value depends on the flow. The VAR-Plus allows air-mixing $\left(\mathrm{F}_{\mathrm{IO}_{2}} 0.5\right)$, but the Oxylator EMX does not.

\section{Statistical Analysis}

Values are given as mean $\pm \mathrm{SD}$, unless specified otherwise. When adequate, data were compared with the chisquare test for qualitative parameters, analysis of variance for repeated measures, and non-parametric Friedman or Wilcoxon rank test for quantitative parameters. $P<.05$ was considered statistically significant. Analyses were performed with statistics software (StatView 5.0, SAS Institute, Cary, North Carolina).

\section{Results}

None of the ventilators provides extensive monitoring, especially the delivered $\mathrm{V}_{\mathrm{T}}$. Only a few combined settings (simultaneous $\mathrm{V}_{\mathrm{T}}$ and respiratory-rate changes) are available. Table 1 describes the ventilators' general characteristics. The pressure-cycled ventilators generated much higher noise levels than the volume-cycled ventilators. With $\mathrm{F}_{\mathrm{IO}_{2}} 0.5$ and high resistance and/or compliance settings, the noise from the VAR-Plus was $83 \mathrm{~dB}$, which is near the limit for the human ear before hearing loss. Gas consumption was much higher with the pressure-cycled ventilators (eg, VAR-Plus $21 \mathrm{~L} / \mathrm{min}$, Medumat Easy $5.5 \mathrm{~L} / \mathrm{min}$ ). Airmixing (during $\mathrm{F}_{\mathrm{IO}_{2}}$ 0.5) was accurate (within $1 \%$ ) with the 2 ventilators on which $\mathrm{F}_{\mathrm{IO}_{2}}$ is adjustable.

The volume-cycled ventilators required the use of an external PEEP valve, whereas with the pressure-cycled ventilators it is inherent to the ventilator's operation, depending on the gas flow and respiratory rate. Most of the ventilators have an alarm only for a fixed maximum pressure, via a pressure-relief valve. The battery life of the EPV100 was 61 hours, 12 min with new batteries.

\section{Tidal Volume}

$\mathrm{V}_{\mathrm{T}}$ was correct and consistent (within 2\%) with the Carevent ALS and Medumat Easy (Fig. 2). With the EPV100 and Pneupac VR1 the set resistance and compliance strongly affected the delivered $\mathrm{V}_{\mathrm{T}}$ (Table 2).

With both the pressure-cycled ventilators (Oxylator EMX and VAR-Plus), delivered $\mathrm{V}_{\mathrm{T}}$ was markedly in- 


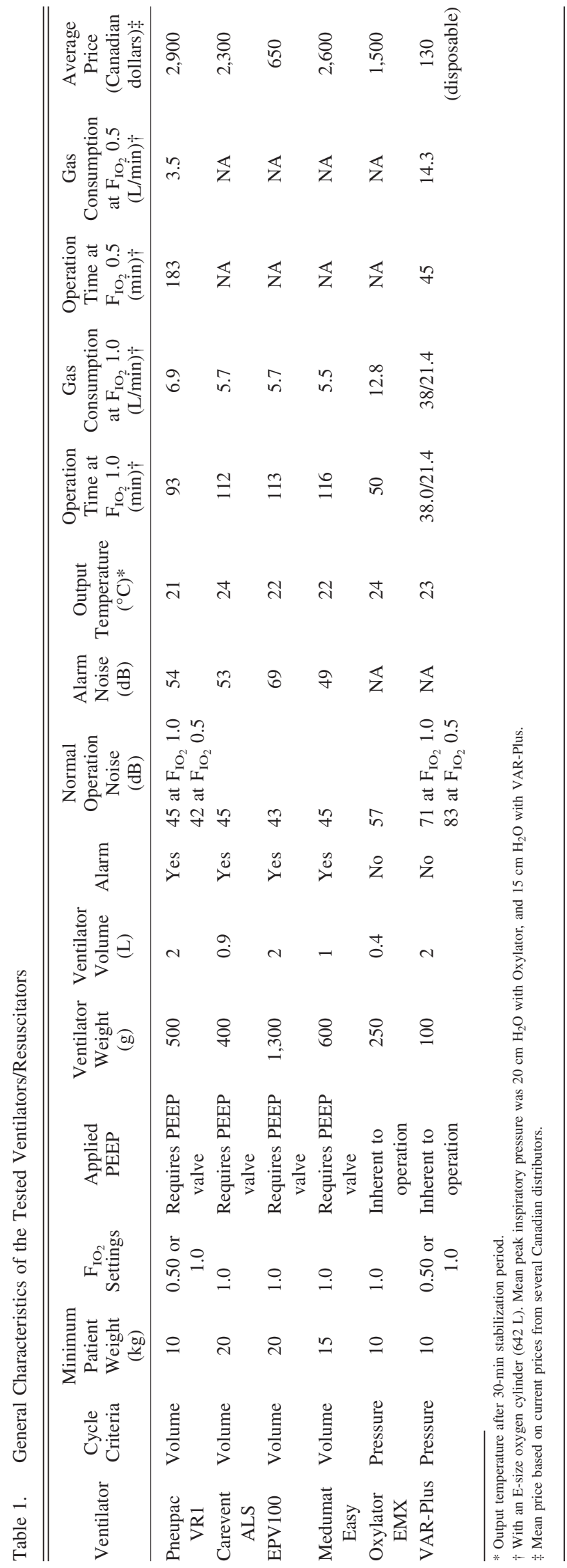

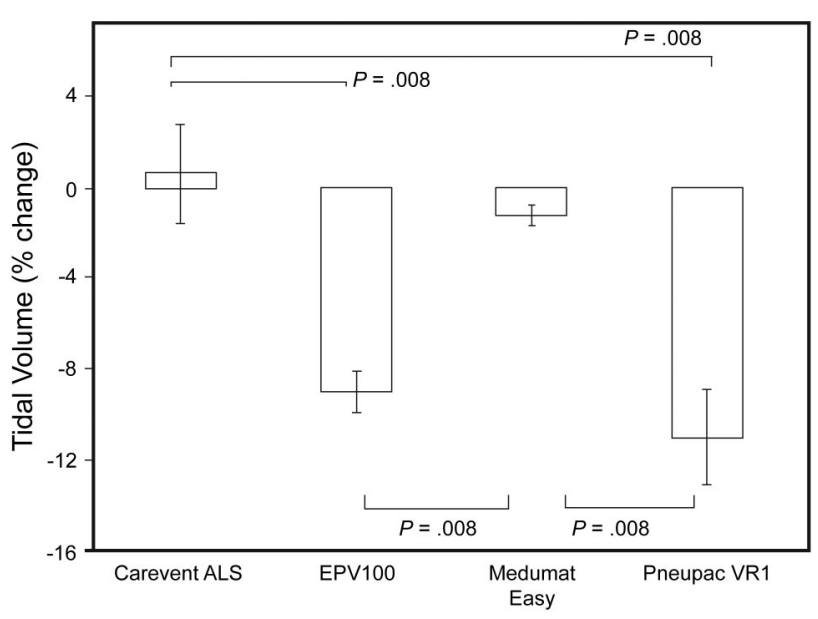

Fig. 2. Mean tidal volume variation over all the $\mathrm{F}_{\mathrm{IO}_{2}}$, compliance, and resistance conditions, with the volume-cycled ventilators.

fluenced by respiratory conditions and inspiratory pressure (Table 3 and Fig. 3). With VAR-Plus the delivered PIP was very different from the set PIP. With the lowest available PIP setting $\left(15 \mathrm{~cm} \mathrm{H}_{2} \mathrm{O}\right.$ ), the delivered PIP was more than $20 \mathrm{~cm} \mathrm{H}_{2} \mathrm{O}$. With a set resistance of $10 \mathrm{~cm} \mathrm{H}_{2} \mathrm{O} / \mathrm{L} / \mathrm{s}$ and a set compliance of $120 \mathrm{~mL} / \mathrm{cm} \mathrm{H}_{2} \mathrm{O}$, safe ventilation was impossible because of major hyperinflation $\left(\mathrm{V}_{\mathrm{T}}>2,000 \mathrm{~mL}\right)$. With VAR-Plus at PIP of $20 \mathrm{~cm} \mathrm{H}_{2} \mathrm{O}$ and compliance of $120 \mathrm{~mL} / \mathrm{cm} \mathrm{H}_{2} \mathrm{O}$, safe ventilation was impossible at any set resistance, because of immediate major hyperinflation $\left(\mathrm{V}_{\mathrm{T}}>2,000 \mathrm{~mL}\right)$. The VAR-Plus manufacturer's proposed initial PIP of $30 \mathrm{~cm} \mathrm{H}_{2} \mathrm{O}$ and "normal" patient resistance of $5 \mathrm{~cm} \mathrm{H}_{2} \mathrm{O} / \mathrm{L} / \mathrm{s}$ and compliance of $70 \mathrm{~mL} / \mathrm{cm} \mathrm{H}_{2} \mathrm{O}$ also resulted in immediate major hyperinflation.

\section{Pressure and Respiratory Rate}

With VAR-Plus, PIP was significantly different with the different PIP settings ( 15 and $20 \mathrm{~cm} \mathrm{H}_{2} \mathrm{O}, P<.001$ ). The PEEP inherent with the pressure-cycled ventilators was highly variable with the resistance, compliance, and PIP settings (see Fig. 3), and between the Oxylator EMX and VAR-Plus. With the VAR-Plus, PEEP was dependent on compliance, whatever the PIP. With the VAR-Plus we observed recurrent operational failures; the VAR-Plus stopped working, then restarted again, without warning or alarm. We found no explanation for that problem. With the Oxylator EMX, at the higher resistance values we observed marked variability in respiratory rate.

\section{Ergonomy and User-Friendliness}

Table 4 and Figure 4 show the results of the ergonomy and user-friendliness tests. Between 5 and 8 objective ergonomy 


\section{Bench Tests of Simple, Handy Ventilators for Pandemics}

Table 2. $\quad$ Measured Tidal Volume Versus Set Resistance, Compliance, and Tidal Volume With the Volume-Cycled Ventilators

\begin{tabular}{|c|c|c|c|c|c|c|c|c|}
\hline Ventilator & $\begin{array}{l}\text { Set } V_{T} \\
(\mathrm{~mL})\end{array}$ & $\underset{(\mathrm{mL})}{\text { Measured } \mathrm{V}_{\mathrm{T}}}$ & $\begin{array}{l}\Delta \mathrm{V}_{\mathrm{T}} \\
(\%)^{*}\end{array}$ & $\underset{(\mathrm{mL})}{\text { Measured }} \mathrm{V}_{\mathrm{T}}$ & $\begin{array}{l}\Delta \mathrm{V}_{\mathrm{T}} \\
(\%)^{*}\end{array}$ & $\underset{(\mathrm{mL})}{\text { Measured }} \mathrm{V}_{\mathrm{T}}$ & $\begin{array}{l}\Delta \mathrm{V}_{\mathrm{T}} \\
(\%)^{*}\end{array}$ & $P$ \\
\hline & & \multicolumn{2}{|c|}{ Set Resistance $5 \mathrm{~cm} \mathrm{H}_{2} \mathrm{O} / \mathrm{L} / \mathrm{s}$} & \multicolumn{2}{|c|}{ Set Resistance $10 \mathrm{~cm} \mathrm{H}_{2} \mathrm{O} / \mathrm{L} / \mathrm{s}$} & \multicolumn{2}{|c|}{ Set Resistance $20 \mathrm{~cm} \mathrm{H}_{2} \mathrm{O} / \mathrm{L} / \mathrm{s}$} & \\
\hline Carevent ALS & 500 & $496 \pm 19$ & -1 & $496 \pm 5$ & -1 & $505 \pm 4$ & +1 & .31 \\
\hline EPV100 & 480 & $438 \pm 5$ & -8 & $438 \pm 5$ & -8 & $434 \pm 4$ & -10 & .001 \\
\hline Medumat Easy & 460 & $455 \pm 3$ & -1 & $454 \pm 2$ & -1 & $453 \pm 1$ & -2 & .70 \\
\hline \multirow[t]{2}{*}{ Pneupac VR1 } & 450 & $416 \pm 9$ & -8 & $412 \pm 6$ & -8 & $401 \pm 10$ & -11 & .001 \\
\hline & & \multicolumn{2}{|c|}{ Set Compliance $30 \mathrm{~mL} / \mathrm{cm} \mathrm{H}_{2} \mathrm{O}$} & \multicolumn{2}{|c|}{ Set Compliance $70 \mathrm{~mL} / \mathrm{cm} \mathrm{H}_{2} \mathrm{O}$} & \multicolumn{2}{|c|}{ Set Compliance $120 \mathrm{~mL} / \mathrm{cm} \mathrm{H}_{2} \mathrm{O}$} & \\
\hline Carevent ALS & 500 & $492 \pm 15$ & -2 & $506 \pm 4$ & +1 & $510 \pm 3$ & +2 & .12 \\
\hline EPV100 & 480 & $432 \pm 2$ & -10 & $438 \pm 2$ & -9 & $441 \pm 3$ & -8 & $<.001$ \\
\hline Medumat Easy & 460 & $454 \pm 4$ & -1 & $454 \pm 1$ & -1 & $454 \pm 1$ & -1 & .95 \\
\hline Pneupac VR1 & 450 & $401 \pm 9$ & -11 & $413 \pm 8$ & -8 & $415 \pm 8$ & -8 & $<.001$ \\
\hline
\end{tabular}

Table 3. Measured PIP, $\mathrm{V}_{\mathrm{T}}$, Inherent PEEP, and Frequency Relative to Set Resistance, Compliance, and Peak Inspiratory Pressure With the Pressure-Cycled Ventilators*

\begin{tabular}{|c|c|c|c|c|c|c|c|}
\hline & $\begin{array}{c}\text { Set PIP } \\
15 \mathrm{~cm} \mathrm{H}_{2} \mathrm{O}\end{array}$ & $\begin{array}{c}\text { Set PIP } \\
20 \mathrm{~cm} \mathrm{H}_{2} \mathrm{O}\end{array}$ & $\begin{array}{c}\text { Set PIP } \\
15 \mathrm{~cm} \mathrm{H}_{2} \mathrm{O}\end{array}$ & $\begin{array}{c}\text { Set PIP } \\
20 \mathrm{~cm} \mathrm{H}_{2} \mathrm{O}\end{array}$ & $\begin{array}{c}\text { Set PIP } \\
15 \mathrm{~cm} \mathrm{H}_{2} \mathrm{O}\end{array}$ & $\begin{array}{c}\text { Set PIP } \\
20 \mathrm{~cm} \mathrm{H}_{2} \mathrm{O}\end{array}$ & $P$ \\
\hline & \multicolumn{2}{|c|}{ Set Resistance $5 \mathrm{~cm} \mathrm{H}_{2} \mathrm{O} / \mathrm{L} / \mathrm{s}$} & \multicolumn{2}{|c|}{ Set Resistance $10 \mathrm{~cm} \mathrm{H} \mathrm{H}_{2} \mathrm{O} / \mathrm{L} / \mathrm{s}$} & \multicolumn{2}{|c|}{ Set Resistance $20 \mathrm{~cm} \mathrm{H}_{2} \mathrm{O} / \mathrm{L} / \mathrm{s}$} & \\
\hline \multicolumn{8}{|l|}{ Oxylator } \\
\hline $\mathrm{PIP}\left(\mathrm{cm} \mathrm{H}_{2} \mathrm{O}\right)$ & $13.7 \pm 0.1$ & $18.0 \pm 0.1$ & $11.9 \pm 1.3$ & $15.4 \pm 2.0$ & $13.7 \pm 0.2$ & $18.0 \pm 0.2$ & .1 \\
\hline $\mathrm{V}_{\mathrm{T}}(\mathrm{mL})$ & $618 \pm 209$ & $936 \pm 325$ & $311 \pm 112$ & $602 \pm 209$ & $157 \pm 17$ & $361 \pm 27$ & .054 \\
\hline $\operatorname{PEEP}\left(\mathrm{cm} \mathrm{H}_{2} \mathrm{O}\right) \dagger$ & $2.6 \pm 0.1$ & $2.7 \pm 0.1$ & $2.3 \pm 0.1$ & $3.7 \pm 2.6$ & $0 \pm 0$ & $5.5 \pm 1.7$ & $<.001$ \\
\hline $\mathrm{f}$ (breaths/min) & $20 \pm 5$ & $15 \pm 3$ & $20 \pm 6$ & $11 \pm 2$ & $12 \pm 1$ & $12 \pm 3$ & .1 \\
\hline \multicolumn{8}{|l|}{ VAR-Plus } \\
\hline PIP $\left(\mathrm{cm} \mathrm{H}_{2} \mathrm{O}\right)$ & $21.1 \pm 0.7$ & $28.1 \pm 0.9$ & $21.3 \pm 0.5$ & $27.8 \pm 1.1$ & $20.5 \pm 0.6$ & $28.1 \pm 0.9$ & .1 \\
\hline $\mathrm{V}_{\mathrm{T}}(\mathrm{mL})$ & $1,101 \pm 536$ & $1,375 \pm 555$ & $968 \pm 445$ & $1,306 \pm 567$ & $610 \pm 212$ & $1,145 \pm 636$ & .004 \\
\hline PEEP $\left(\mathrm{cm} \mathrm{H}_{2} \mathrm{O}\right)$ & $5.1 \pm 0.3$ & $6.3 \pm 0.3$ & $5.2 \pm 0.3$ & $6.3 \pm 0.4$ & $5.6 \pm 0.3$ & $6.7 \pm 0.5$ & .1 \\
\hline \multirow[t]{2}{*}{ f (breaths/min) } & $15 \pm 7$ & $16 \pm 3$ & $14 \pm 6$ & $15 \pm 1$ & $13 \pm 4$ & $16 \pm 2$ & .1 \\
\hline & \multicolumn{2}{|c|}{ Set Compliance $30 \mathrm{~mL} / \mathrm{cm} \mathrm{H}_{2} \mathrm{O}$} & \multicolumn{2}{|c|}{ Set Compliance $70 \mathrm{~mL} / \mathrm{cm} \mathrm{H}_{2} \mathrm{O}$} & \multicolumn{2}{|c|}{ Set Compliance $120 \mathrm{~mL} / \mathrm{cm} \mathrm{H}_{2} \mathrm{O}$} & \\
\hline \multicolumn{8}{|l|}{ Oxylator } \\
\hline $\mathrm{PIP}\left(\mathrm{cm} \mathrm{H}_{2} \mathrm{O}\right)$ & $13.6 \pm 0.5$ & $16.6 \pm 2.7$ & $13.2 \pm 0.9$ & $18.0 \pm 0.1$ & $12.4 \pm 2.0$ & $16.8 \pm 2.0$ & .1 \\
\hline $\mathrm{V}_{\mathrm{T}}(\mathrm{mL})$ & $190 \pm 39$ & $274 \pm 60$ & $467 \pm 132$ & $688 \pm 130$ & $532 \pm 239$ & $947 \pm 316$ & .01 \\
\hline $\operatorname{PEEP}\left(\mathrm{cm} \mathrm{H}_{2} \mathrm{O}\right)$ & $2.5 \pm 0.1$ & $2.2 \pm 2.1$ & $2.5 \pm 0.2$ & $2.3 \pm 2.5$ & $2.5 \pm 0.4$ & $4.7 \pm 4.1$ & .07 \\
\hline f (breaths/min) & $28 \pm 7$ & $21 \pm 2$ & $16 \pm 2$ & $10 \pm 2$ & $8 \pm 2$ & $7 \pm 0$ & .007 \\
\hline \multicolumn{8}{|l|}{ VAR-Plus } \\
\hline PIP $\left(\mathrm{cm} \mathrm{H}_{2} \mathrm{O}\right)$ & $20.5 \pm 0.4$ & $27.6 \pm 1.1$ & $21.3 \pm 0.6$ & $28.4 \pm 0.9$ & $21.1 \pm 0.9$ & ND & .1 \\
\hline $\mathrm{V}_{\mathrm{T}}(\mathrm{mL})$ & $418 \pm 49$ & $583 \pm 86$ & $884 \pm 201$ & $1,243 \pm 248$ & $1,377 \pm 444$ & $>2,000$ & $<.001$ \\
\hline $\operatorname{PEEP}\left(\mathrm{cm} \mathrm{H}_{2} \mathrm{O}\right)$ & $4.0 \pm 0.2$ & $6.2 \pm 0.6$ & $5.4 \pm 0.3$ & $6.7 \pm 0.2$ & $5.6 \pm 0.3$ & ND & $<.001$ \\
\hline f (breaths/min) & $20 \pm 3$ & $19 \pm 1$ & $13 \pm 2$ & $12 \pm 0$ & $9 \pm 1$ & ND & .004 \\
\hline \multicolumn{8}{|c|}{$\begin{array}{l}* \text { Values are mean } \pm \text { SD. } \\
\dagger \text { PEEP inherent to the operation these pressure-cycled ventilators. } \\
\text { PIP }=\text { peak inspiratory pressure } \\
V_{T}=\text { tidal volume } \\
\mathrm{f}=\text { frequency } \\
\mathrm{ND}=\text { no data collected }\end{array}$} \\
\hline
\end{tabular}

tests were performed with each ventilator, with 6 respiratory therapists and 6 emergency physicians, so there were 30-48 tests of each ventilator. Alarm silencing was only possible on the EPV100, but 4 of the 6 respiratory therapists and 4 of the 6 emergency physicians failed in the silence-alarm task. Table 4 shows the overall task-failure rates. Installation of the 

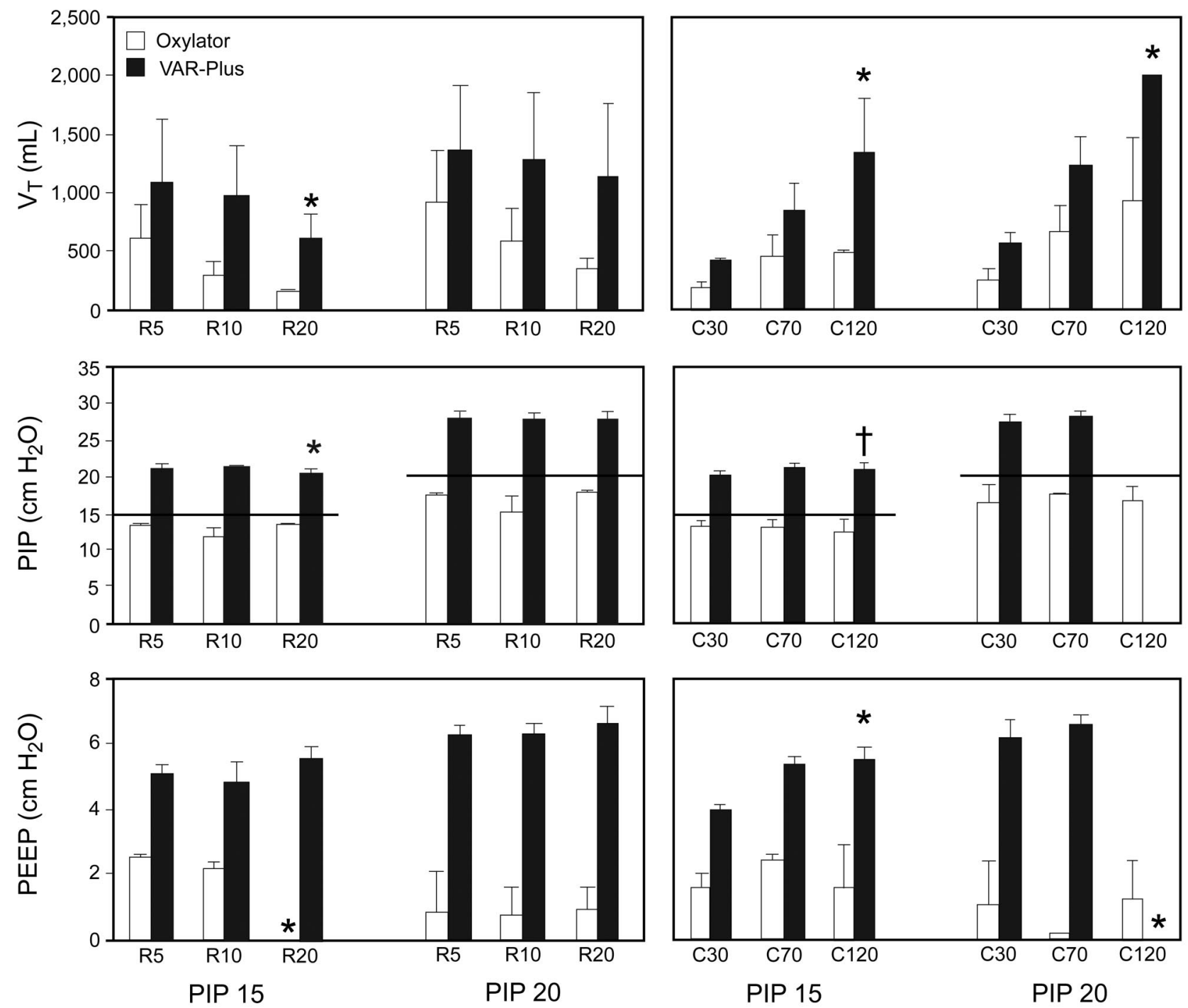

Fig. 3. Measured tidal volume $\left(\mathrm{V}_{\mathrm{T}}\right)$, measured peak inspiratory pressure (PIP), and measured PEEP (inherent to these ventilators' operation) with the pressure-cycled ventilators, at set PIP values of 15 and $20 \mathrm{~cm} \mathrm{H}_{2} \mathrm{O}$ (indicated by the solid lines), set resistance values of 5,10 , and $20 \mathrm{~cm} \mathrm{H}_{2} \mathrm{O} / \mathrm{L} / \mathrm{s}$ (R5, R10, and R20), and set compliance values of 30, 70, and $120 \mathrm{~mL} / \mathrm{cm} \mathrm{H} \mathrm{H}_{2} \mathrm{O}(\mathrm{C} 30, \mathrm{C} 70$, and C120). The data bars indicate the mean values, and the error bars represent the standard deviations. With the VAR-Plus, measured PIP was significantly different from the set PIP. There was major variability in delivered $\mathrm{V}_{\mathrm{T}}$ during single tests (standard deviation of 50-100\%). ${ }^{*} P=.005 . \dagger P<.001$.

circuit and reading the alarm settings had significantly more task-failures with the Carevent ALS and the EPV100 $(P=.001)$. The subjective user-friendliness surveys found several important differences (see Table 4).

\section{Discussion}

Several evaluations of disaster-type ventilators have been published, ${ }^{5-8}$ but to our knowledge this is the first to evaluate technical performance, autonomy, and ergonomy of ventilators (often called "resuscitators") designed for masscasualty events. Our main findings are:
- The pressure-cycled ventilators we tested, Oxylator EMX and VAR-Plus, should be ruled out because of the major impact of compliance and resistance on delivered $\mathrm{V}_{\mathrm{T}}$, and because of their high gas consumption. Our results suggest that Oxylator EMX and VAR-Plus would cause either hypoventilation (in a patient with low respiratory compliance) or severe barotrauma/volutrauma (in a patient with normal to high respiratory compliance).

- Despite their technical simplicity, the Carevent ALS and Medumat Easy volume-cycled ventilators had reliable performance at the compliance or resistance settings we tested. 


\section{Bench Tests of Simple, Handy Ventilators for Pandemics}

Table 4. Ergonomy and User-Friendliness Assessment

\begin{tabular}{|c|c|c|c|c|c|c|}
\hline \multirow[b]{2}{*}{ Ventilator } & \multicolumn{2}{|c|}{$\begin{array}{l}\text { Task-Failure Rate } \\
\text { (failures/attempts) }\end{array}$} & \multicolumn{2}{|c|}{$\begin{array}{c}\text { Median } \\
\text { Ease-of-Use } \\
\text { Score* }\end{array}$} & \multicolumn{2}{|c|}{$\begin{array}{c}\text { Median } \\
\text { Will-to-Use } \\
\text { Score } \dagger\end{array}$} \\
\hline & RTs & MDs & RTs & MDs & RTs & MDs \\
\hline Pneupac VR1 & $0 / 42$ & $0 / 42$ & 4.0 & 4.0 & 2.0 & 3.5 \\
\hline Carevent ALS & $5 / 42$ & $7 / 42 \ddagger$ & 5.0 & 4.0 & 2.3 & 4.0 \\
\hline EPV100 & $10 / 48 \S$ & $6 / 48 \ddagger$ & 4.5 & 5.0 & 2.5 & 2.5 \\
\hline Medumat Easy & $0 / 42$ & $0 / 42$ & 4.0 & 3.8 & 3.5 & 3.0 \\
\hline Oxylator EMX & $2 / 36$ & $1 / 36$ & $2.0 \|$ & 4.5 & $1.0 \mathrm{I}$ & $2.0 \|$ \\
\hline VAR-Plus & $0 / 30$ & $0 / 30$ & 3.5 & 2.5 & $1.5 \mathbb{I}$ & $1.0 \|$ \\
\hline \multicolumn{7}{|c|}{$\begin{array}{l}\text { * Ease-of-use scale: } 1=\text { very difficult through } 5=\text { very easy. } \\
\dagger \text { Will-to-use scale: } 1=\text { certainly not through } 5=\text { certainly. } \\
\$ P<.05 \text { as compared to all except EPV } 100 \text { and Carevent ALS. } \\
\S P=.005 \text { as compared to all except Carevent ALS. } \\
\| P<.05 \text { as compared to Carevent ALS. } \\
\text { II } P<.05 \text { as compared to Carevent ALS and Medumat Easy; } \\
\mathrm{RT}=\text { respiratory therapist } \\
\mathrm{MD}=\text { emergency physician }\end{array}$} \\
\hline
\end{tabular}

- Ergonomy evaluation may help to choose an disaster ventilator.

- Only the Pneupac VR1 and VAR-Plus have adjustable $\mathrm{F}_{\mathrm{IO}_{2}}$, though all the tested ventilators can be connected to compressed air instead oxygen.

Disaster may create thousands of critically ill patients requiring mechanical ventilation and may force difficult allocation decisions when demand greatly exceeds supply. ${ }^{9}$ Most critical care units routinely function at or near capacity, ${ }^{10}$ and thus have very limited capability for disasters. ${ }^{11,12}$ Certain shortages can be prevented by stockpiling, but many medical supplies are maintained only in quantities sufficient for daily operations, so stepwise changes in resource use may be necessary to maintain the best possible care for the resource scarcity, as suggested by the Task Force for Mass Critical Care. ${ }^{9}$ For several complex, durable devices, such as ventilators, there are few acceptable alternatives. ${ }^{12,13}$ In some circumstances, temporizing measures such as manual ventilation with bag/ valve/mask may be adequate, but such strategies will probably be inadequate for disasters that necessitate days of ventilatory support, so small, low-cost ventilators ("resuscitators") such as those we evaluated may be of major interest and may substantially increase the ability to treat disaster patients.

Stockpiled mechanical ventilation equipment for mass casualties should have broad utility. The ideal ventilator will meet the anticipated requirements of adults and pediatric victims with various pathologies, with patients with or without preliminary pulmonary conditions; should be safe to operate (ie, technically efficient but also ergonomic); and should be inexpensive to purchase and maintain. ${ }^{14}$
If several disaster and transport ventilators evaluations are already available, we choose to concentrate our study on smaller ventilators, on the assumption that a smaller ventilator should be easier and more efficient to stockpile and possibly be more ergonomic.

The pressure-cycled ventilators we tested, Oxylator EMX and VAR-Plus, have been proposed for emergency and short-term ventilatory support in mass-casualty scenarios, but there are few reports of their successful use. ${ }^{15}$ After hurricane Katrina, the Vortran VAR-Plus could be used only with patients who had nonpulmonary reasons for mechanical ventilation (eg, head injury). ${ }^{16}$ In a laboratory evaluation, ${ }^{17}$ the VAR-Plus was recommended for emergency ventilation only with great caution, because of its variable performance under changing load: minute ventilation ranged from zero to $9.8 \mathrm{~L} / \mathrm{min}$, resulting in a calculated $\mathrm{P}_{\mathrm{aCO}}$ range of over 16 to $100 \mathrm{~mm} \mathrm{Hg}$, never in the normal range. Our study, as others, ${ }^{18}$ confirms the major influence of compliance and resistance on $\mathrm{V}_{\mathrm{T}}$ with VARPlus and Oxylator EMX. Since $V_{T}$ may change with these ventilators according to the patient's condition, continuous monitoring will be mandatory with VAR-Plus or Oxylator EMX, though we do not know what monitoring will be available (end-tidal carbon dioxide? blood gases?). Moreover, we observed recurrent operation failures with VARPlus, which stopped working and restarted without alarm or warning. Others ${ }^{17,19}$ have found that such technical failure can severely impair a hypoxemic patient's condition. Another cautionary note about these pressure-cycled ventilators is that the user cannot set the PEEP, and since PEEP is critical in the management of acute respiratory distress, this rules out these ventilators for stockpiling.

Delivered $\mathrm{V}_{\mathrm{T}}$ was accurate and consistent with the Carevent ALS and Medumat Easy volume-cycled ventilators. The EPV100 and Pneupac VR1 had $\mathrm{V}_{\mathrm{T}}$ variability of $8-11 \%$, but always below the set limit. This difference was not due to crossing the pressure limit threshold, nor to the inability of the driving system to generate the required pressure. It may, however, be explained either by the compressible volume of the ventilator circuit, or most certainly by the ventilator design. The influence of resistance and compliance on delivered $V_{T}$ with the EPV100 and Pneupac VR1 could be considered clinically minor, so we consider EPV100 and Pneupac VR1 adequate as disaster ventilators. Some researchers think EPV100 and Pneupac VR1 should not be proposed as a first alternative to standard emergency ventilators, given the lack of monitoring with EPV100 and Pneupac VR1, ${ }^{14}$ but, in fact, $\mathrm{V}_{\mathrm{T}}$ reliability with these ventilators may be substantially higher than that with standard emergency ventilators. ${ }^{5}$ The important difference between these disaster ventilators and standard emergency ventilators is the absence of disconnection alarms, which is, of course, a major patient-safety issue, 


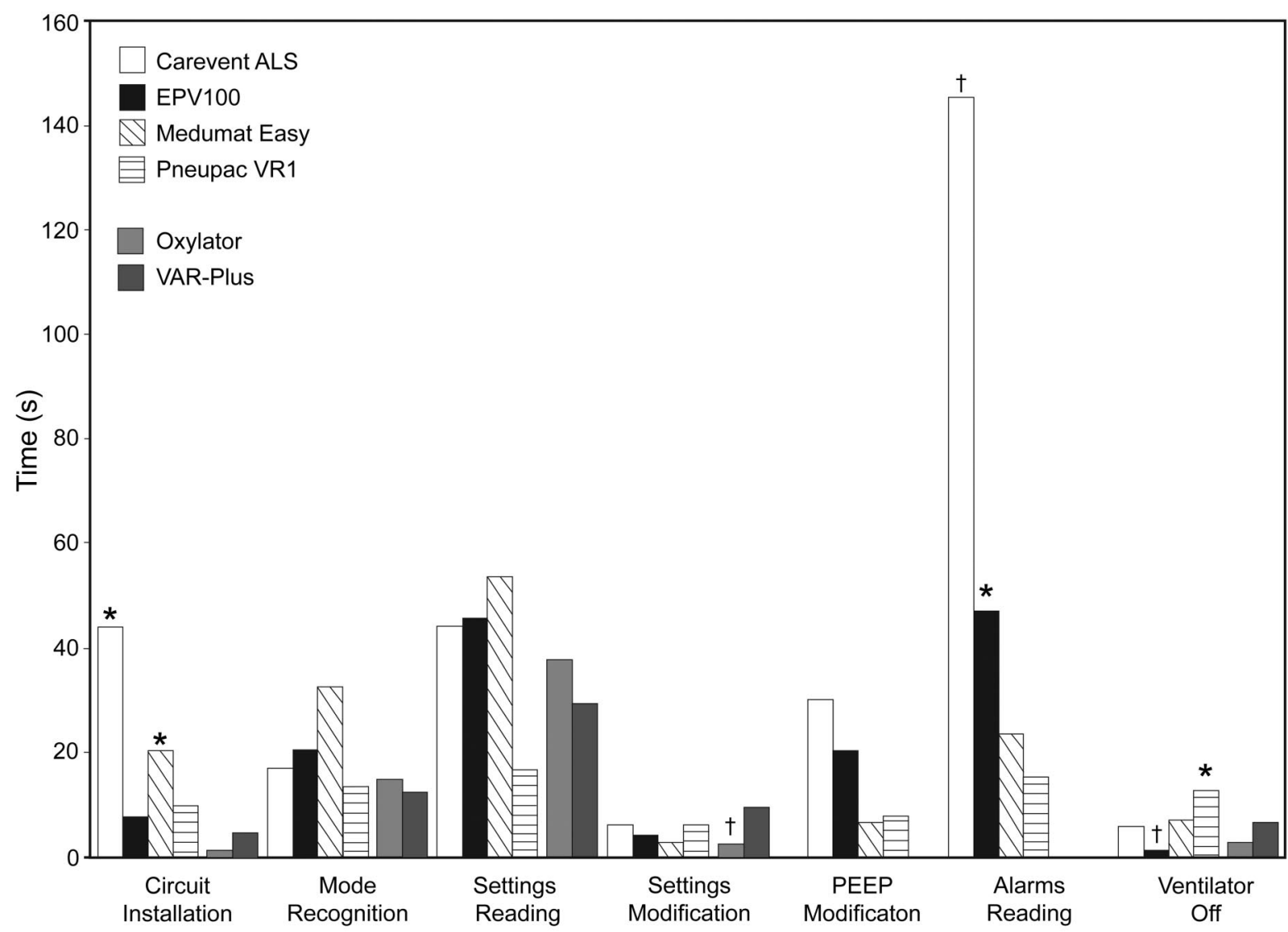

Fig. 4. Ergonomy test results. The data bars represent the median times to complete the ventilator set-up and adjustment tasks. After 180 seconds a task was considered failed. Alarm silencing was only possible with the EPV100, so it is not shown. Alarm reading time was longest with the Carevent ALS, whereas it is only represented by the maximum pressure value for the relief valve, which is written in a very small font. ${ }^{*} P=.03$. $\dagger P=.005$.

but not less than a reliable delivered $\mathrm{V}_{\mathrm{T}}$ that is independent of the patient's characteristics.

A disaster ventilator's autonomy (gas consumption and electrical supply) must be considered. Ideally, it should have minimal gas consumption, ${ }^{20}$ because in a mass-casualty event the oxygen demand will suddenly increase, while oxygen supply resources may be eliminated. ${ }^{21}$ The ability to set the $\mathrm{F}_{\mathrm{IO}_{2}}$ and to use compressed air instead of pure oxygen is also important. Only the Pneupac VR1 and VARPlus have $\mathrm{F}_{\mathrm{IO}_{2}}$ settings, but all the tested ventilators can use compressed air or oxygen. The volume-cycled ventilators had much lower gas consumption: $90-115 \mathrm{~min}$ of ventilation on a full E-size oxygen cylinder, as compared to 30-77 min with most standard emergency ventilators. ${ }^{5}$ Without considering other potential technical drawbacks, we conclude that pressure-cycled ventilators should be avoided because of their high gas consumption.

All of the tested volume-cycled ventilators have a single control for $\mathrm{V}_{\mathrm{T}}$ and respiratory rate, which enables quick set-up. However, with most disaster ventilators these standardized settings are few and certainly not in accord with modern ventilation standards: for example, huge $\mathrm{V}_{\mathrm{T}}$ plus low respiratory rate rather than small $\mathrm{V}_{\mathrm{T}}$ and high respiratory rate. ${ }^{22}$ This problem could be important, especially in small adults and pediatric patients, whereas low $\mathrm{V}_{\mathrm{T}}$ is probably the most important feature of lung-protective ventilation. ${ }^{23}$ Monitoring in that situation will require clinical supervision, but may be assisted by capnometry, which substantially increases the cost and complicates the use, but may allow adequate ventilation and satisfactory patient safety.

Increasing the number of ventilators available for a masscasualty response also requires increasing human resources to care for ventilated patients. This human resource issue is a key factor in ventilator selection-of no less importance than the ventilator itself. An ideal disaster ventilator should be intuitive and easy to use, ${ }^{20}$ so that less-trained personnel can use it. The more ergonomic and user-friendly the ventilator, the safer the patients should be, because less-trained staff may be able to manage ventilation issues and alarms. Few studies have dealt with the importance of ergonomy and user-friendliness of critical care, emergency, or home-care ventilators, ${ }^{24-26}$ and none with that of disaster ventilators. This evaluation is important, to identify and 


\section{Bench Tests of Simple, Handy Ventilators for Pandemics}

address problems that may occur in stressful field use by less-trained personnel. In many cases, the ventilator-taskfailure rate may be substantially improved by very simple design modifications. Ventilation-setting modifications were significantly shorter with the Oxylator EMX $(P=.006)$, mainly because only a modification of the pressure is possible, and the respiratory rate depends only on the flow; there are no other adjustable settings. The EPV100 seemed less ergonomic than the other volumecycled ventilators to both the respiratory therapists and the emergency physicians. This difference, which is much more important to the overall task-failure rate, was due mainly to difficulties in trying to shut down the alarms, which is a function that is unavailable with the other ventilators. Our subjective user-friendliness assessment found several important differences, though the differences between individuals are difficult to explain. These findings, taken together with the individual test durations for each ventilator, allow a better-informed choice of disaster ventilator, depending of the main objective for its use and the field of operation. A closer relationship between end-users and manufacturers should be promoted during ventilator development, based on scientific evaluation of users' cognitive processes in the clinical setting.

\section{Limitations}

The main limitation of this study is that it did not involve patients. However, we simulated various situations and combinations that can be encountered in the clinical field. Until now, disaster ventilators have not been considered adequate for use in such a setting of interest ${ }^{19}$ because of their lack of evaluation. We believe our benchtest results at least allow reconsidering that position.

Second, concerning our ergonomy and user-friendliness assessment, though the profile of our test participants is representative of Canadian emergency physicians and respiratory therapists, we cannot necessarily extrapolate our results to other users such as intensive-care physicians, emergency physicians in other countries, or emergency nurses.

Third, concerning ergonomy and user-friendliness, our objective was not to describe the full extent of the difficulties clinicians may face with disaster ventilators, but, rather, to evaluate potential ventilator-operation task-failures that might occur in a mass-casualty situation where human resources are overwhelmed. Thus, we blinded our test participants about their use, did not give them prior access to the ventilator manuals, and they received no explanations about the ventilators. Of course, clinicians should be trained before using a new ventilator, but in a disaster situation there may be no training or the training may be cursory, so we replicated that situation. Moreover, some clinicians have few opportunities to use ventilators and may therefore forget some of their training.

\section{Conclusions}

We found a huge heterogeneity of performance, gas consumption, and ergonomy in the 6 tested ventilators. The Oxylator EMX and VAR-Plus pressure-cycled ventilators should be ruled out because of unreliable and unpredictable performance, especially given that monitoring (eg, end-tidal carbon dioxide) may not be available in a mass-casualty situation. The Carevent ALS and Medumat Easy volume-cycled ventilators were technically efficient and reliable; their gas consumption was less than that of conventional emergency ventilators. We believe that the reliability, portability, and ease of use of these disaster ventilators makes them valuable for mass-casualty events.

\section{ACKNOWLEDGMENTS}

We thank François Lellouche MD, Institut Universitaire de Cardiologie et de Pneumologie de l'Université Laval, Québec, Canada, for help in designing the performance tests.

\section{REFERENCES}

1. American Association for Respiratory Care. Guidelines for acquisition of ventilators to meet demands for pandemic flu and mass casualty incidents. May 25, 2006 http://www.aarc.org/resources/ vent_guidelines.pdf. Accessed April 8, 2011.

2. Anderson TA, Hart GK, Kainer MA. Pandemic influenza - Implications for critical care resources in Australia and New Zealand. J Crit Care 2003;18(3):173-180.

3. Wax RS, Kenny L, Burns P. Educating providers of mechanical ventilation: an update. Curr Opin Crit Care 2006;12(1):61-66.

4. Gottlieb D, Lozano S, Arntz J, et al. Assessing the educational status of clinicians concerning mechanical ventilation. IFBME Proc 2009; 22:2753-2756.

5. Chipman DW, Caramez MP, Miyoshi E, Kratohvil JP, Kacmarek RM. Performance comparison of 15 transport ventilators. Respir Care 2007;52(6):740-751.

6. Nolan JP, Baskett PJ. Gas-powered and portable ventilators: an evaluation of six models. Prehosp Disaster Med 1992;7(1):25-34.

7. McGough EK, Banner MJ, Melker RJ. Variations in tidal volume with portable transport ventilators. Respir Care 1992;37(3):233-239.

8. Zanetta G, Robert D, Guérin C. Evaluation of ventilators used during transport of ICU patients - a bench study. Intensive Care Med 2002; 28(4):443-451.

9. Rubinson L, Hick JL, Hanfling DG, Devereaux AV, Dichter JR, Christian MD, et al. Definitive care for the critically ill during a disaster: a framework for optimizing critical care surge capacity: from a Task Force for Mass Critical Care summit meeting, January 26-27, 2007, Chicago, IL. Chest 2008;133(5 Suppl):18S-31S.

10. Halpern NA, Pastores SM, Thaler HT, Greenstein RJ. Changes in critical care beds and occupancy in the United States 1985-2000: differences attributable to hospital size. Crit Care Med 2006;34(8): 2105-2112.

11. Daugherty EL, Branson R, Rubinson L. Mass casualty respiratory failure. Curr Opin Crit Care 2007;13(1):51-56. 


\section{Bench Tests of Simple, Handy Ventilators for Pandemics}

12. Hick JL, Rubinson L, O'Laughlin DT, Farmer JC. Clinical review: allocating ventilators during large-scale disasters-problems, planning, and process. Crit Care 2007;11(3):217.

13. Neyman G, Irvin CB. A single ventilator for multiple simulated patients to meet disaster surge. Acad Emerg Med 2006;13(11):12461249.

14. Rubinson L, Branson RD, Pesik N, Talmor D. Positive-pressure ventilation equipment for mass casualty respiratory failure. Biosecur Bioterror 2006;4(2):183-194.

15. Nates JL. Combined external and internal hospital disaster: impact and response in a Houston trauma center intensive care unit. Crit Care Med 2004;32(3):686-690.

16. Romano M, Raabe OG, Walby W, Albertson TO. The stability of arterial blood gases during transportation of patients using the RespirTech PRO. Am J Emerg Med 2000;18(3):273-277.

17. Babic MD, Chatburn RL, Stoller JK. Laboratory evaluation of the Vortran Automatic Resuscitator Model RTM. Respir Care 2007; 52(12):1718-1727.

18. Branson RD, Davis K, Johannigman JA. Evaluation of portable automatic resuscitators under changing impedance conditions: a lung model study (abstract). Respir Care 2004;49(11):1436.
19. ECRI Institute. Vortran VAR gas-powered resuscitators (also referred to as the Surevent) may spontaneously stop delivering breaths. Health Devices 2007;36(12):404-406.

20. Branson RD, Johannigman JA, Daugherty EL, Rubinson L. Surge capacity mechanical ventilation. Respir Care 2008;53(1):78-88.

21. Ritz RH, Previtera JE. Oxygen supplies during a mass casualty situation. Respir Care 2008;53(2):215-224; discussion 224-225.

22. Phua GC, Govert J. Mechanical ventilation in an airborne epidemic. Clin Chest Med 2008;29(2):323-328.

23. Yilmaz M, Gajic O. Optimal ventilator settings in acute lung injury and acute respiratory distress syndrome. Eur J Anaesthesiol 2008; 25(2):89-96.

24. Vignaux L, Tassaux D, Jolliet P. Evaluation of the user-friendliness of seven new generation intensive care ventilators. Intensive Care Med 2009;35(10):1687-1691.

25. Templier F, Miroux P, Dolveck F, Descatha A Goddet NS, Jeleff C, et al. Evaluation of the ventilator-user interface of 2 new advanced compact transport ventilators. Respir Care 2007;52(12):1701-1709.

26. Gonzalez-Bermejo J, Laplanche V, Husseini FE, Duguet A, Derenne JP, Similowski T. Evaluation of the user-friendliness of 11 home mechanical ventilators. Eur Respir J 2006;27(6):1236-1243.

This article is approved for Continuing Respiratory Care Education credit. For information and to obtain your CRCE

(free to AARC members) visit www.RCJournal.com 